\title{
SEJARAH DAN SPESIFIK PRODUK TOSHIBA
}

\author{
Alifa Khairunnisa \\ 185100011 \\ Fakultas Komputer \\ Alifakhairunnisa.Student@umitra.ac.id
}

\begin{abstract}
TOSHIBA

Toshiba adalah perusahaan Jepang yang memproduksi dan memasarkan berbagai peralatan listrik dan produk elektronik yang canggih, yang berkantor pusat di Tokyo, Jepang. Toshiba dinilai sebagai perusahaan no 7 dunia untuk produsen terintegrasi untuk peralatan listrik, elektronik dan sebagai pembuat chip. Toshiba Semikonduktor termasuk 20 besar pemimpin penjualan semikonduktor di
\end{abstract} dunia.

Kata kunci : Sejarah dan spesifik produk toshiba 


\section{A. PENDAHULUAN}

Toshiba adalah perusahaan Jepang yang memproduksi dan memasarkan berbagai peralatan listrik dan produk elektronik yang canggih, yang berkantor pusat di Tokyo, Jepang. Toshiba dinilai sebagai perusahaan no 7 dunia untuk produsen terintegrasi untuk peralatan listrik, elektronik dan sebagai pembuat chip. Toshiba Semikonduktor termasuk 20 besar pemimpin penjualan semikonduktor di dunia.

Toshiba dibentuk pada tahun 1939, merupakan hasil merger dari dua perusahaan. Tokyo Denki adalah perusahaan yang bergerak dibidang consumer goods dan perusahaan mesin Shibaura Seisakusho. Mengambil beberapa huruf didepan dari masing-masing perusahaan "TO" dan "SHIBa" maka lahirlah merek Toshiba. Pada tahun 1984 perusahaan itu resmi berubah menjadi Toshiba Corporation. Grup ini makin kuat melalui pertumbuhan internal dan melalui akuisisi perusahaan rekayasa alat berat dan perusahaan industri primer pada 1940-an dan 1950-an. Kemudian pada 1970-an dan seterusnya, anak perusahaan mulai didirikan, yaitu: grup Toshiba Lighting \& Teknologi (1989), Toshiba Carrier Corporation (1999), Toshiba Elevator \& Building System Corp (2001), Toshiba Solutions Corp (2003), Toshiba Medical Systems Corp (2003) dan Toshiba Materials Co Ltd (2003).

\section{B. PEMBAHASAN / STUDI KASUS}

Toshiba Corporation adalah salah satu perusahaan diversifikasi produsen dan pemasar produk digital, perangkat elektronik dan komponen, sistem infrastruktur sosial dan Home appliances. Sebagai pendiri dan inovator terkemuka dalam komputasi portabel dan produk-produk jaringan, Toshiba mulai memasarkan notebook, PC, dan PC server untuk rumah, kantor dan pengguna mobile. Toshiba Qosmio Notebook PC memimpin jalan dalam konvergensi komputasi dan kemampuan, menawarkan konsumen yang lengkap solusi hiburan pribadi. Sementara itu, seri "Tipis dan Ringan" membawa tingkat mobilitas tinggi dan daya tahan untuk notebook PC untuk penggunaan bisnis di era ini.

Toshiba memproduksi semua jenis laptop, dari model Libretto yang lucu dan ultra portabel sampai model multimedia Qosmio keren. Laptop Toshiba juga populer di Amerika dan Eropa. Apakah pengguna mencari pengganti desktop, laptop untuk mahasiswa atau laptop untuk game, akan ada sesuatu yang cocok bagi mereka di antara rangkaian yang tak terhitung jumlahnya seperti notebook Toshiba Libretto, Portege, Qosmio, Satellite dan Portege.

Tapi artikel ini lebih menekankan 
pada produk dan spesifik laptop merk toshiba sejak awal rilis hingga akhir.

\section{1. (1985) Toshiba T1100}

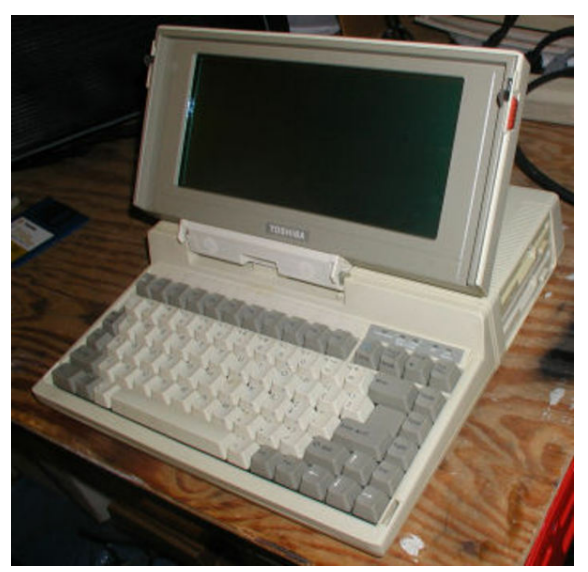

T1100 adalah laptop produksi Toshiba dan toshiba menyebutkan bahwa Laptop T1100 "the worlds first mass-market laptop computer". Spesifikasi teknis itu sebanding dengan IBM Original. Prosesor dari laptop ini menggunakan Intel 80C88, 4.77MHz

2. (1986) Toshiba T3100

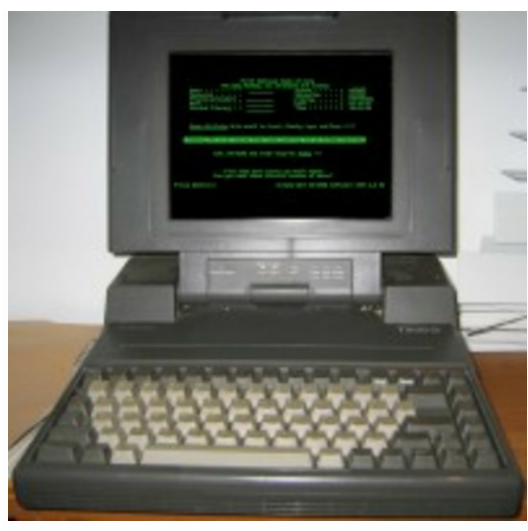

Laptop buatan toshiba tahun 1986 ini memiliki, $10 \mathrm{MB}$ Harddrive, 8 $\mathrm{MHz}$ Intel 80286 CPU. Yoshiba mengatakan bahwa laptop ini adalah "World First Notebook PC with an Intel 286 Processor"

\section{3. (1988) Toshiba T3100 E}

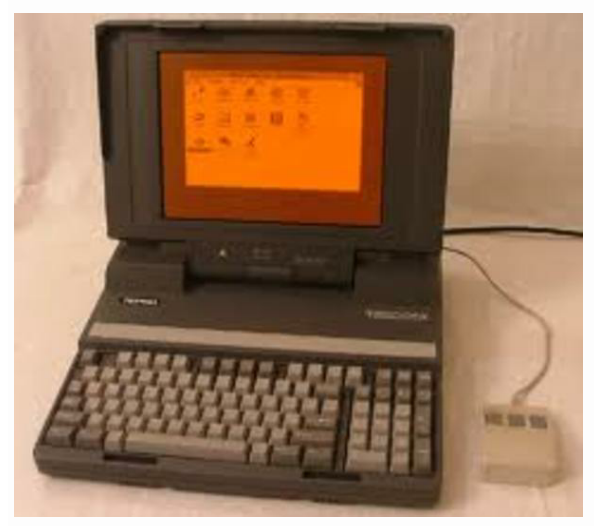

Laptop toshiba tahun keluaran 1988 inidisebut laptop pertama dunia yang menggunakan internal Hard Disk Drive dengan kapasitas $20 \mathrm{MB}$.

4. (1991) Toshiba T4400 


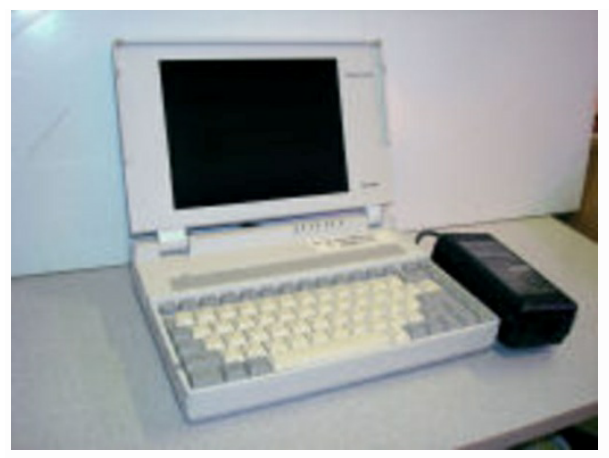

Laptop garapan Toshiba tahun 1991 ini dikatakan sebagai "World's First Notebook PC with an Active Matrix Screen"

\section{5. (1994) Toshiba Tecra CS/CDT}

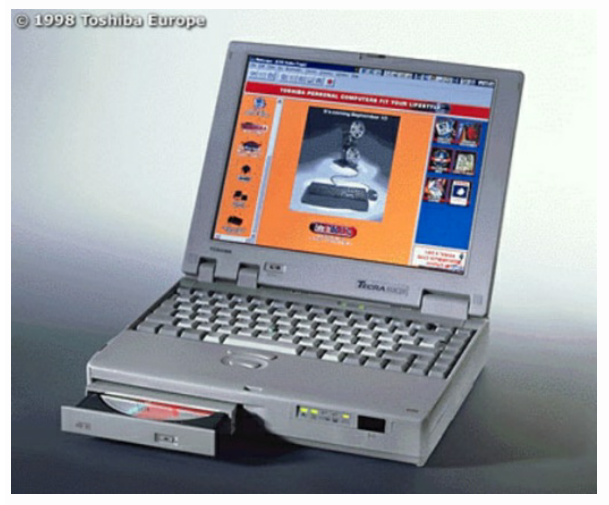

Lapop toshiba ini adalah laptop pertama dunia yang menggunakan intel pentium.

\section{6. (1995) Toshiba Tecra T6600 C}

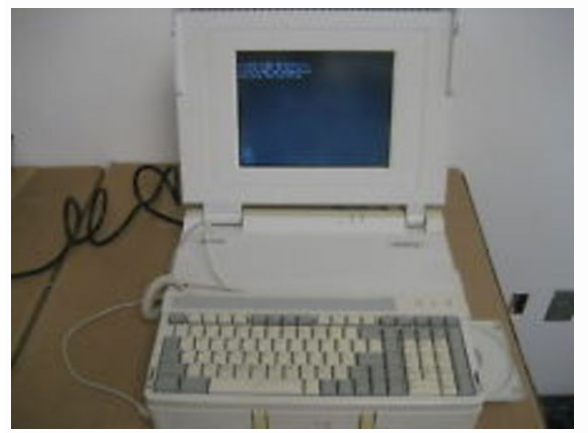

Laptop ini adalah laptop pertama dunia dengan menggunakan baterai Lithium-ion.

\section{7. (1997) Toshiba Libretto 50}

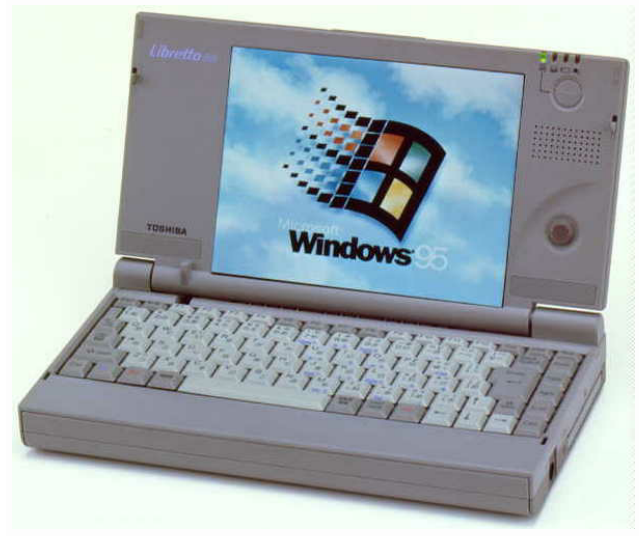

Laptop keluaran toshiba tahun 1997 ini adalah laptop pertama dunia yang menggunakan windows 95 secara penuh.

\section{8. (2001) Toshiba Portege 4000}

\section{Toshiba Portégé ${ }^{\circledR}$ 4000}

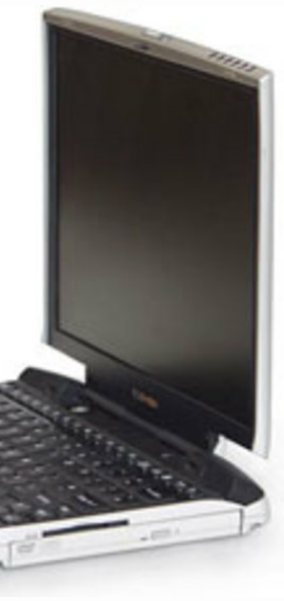

Laptop keluaran 2001 ini adalah laptop pertama di dunia dengan teknologi wireless. Laptop ini berkapastitas $20 \mathrm{~GB}$, dan baterai dari laptop ini dapat bertahan hidup 3,5 jam 


\section{9. (2003) Toshiba Satellite P25} Series

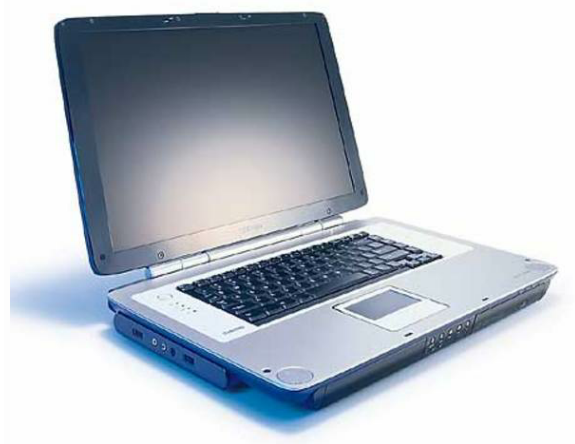

Laptop toshiba pertama di dunia dengan layar Widescreen 17 inch.

\section{0. (2005) Toshiba Tecra S3}

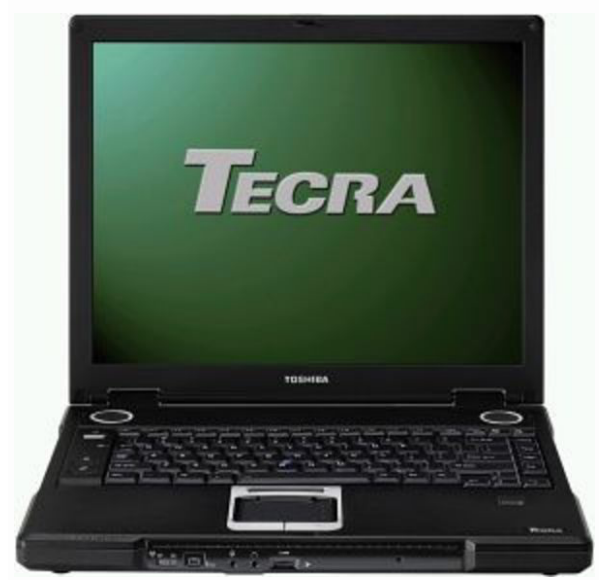

Laptop toshiba keluaran tahun 2005 ini adalah lapop pertama dunia dengan RoHS-Compliant.

11. (2007) Toshiba Protege R500

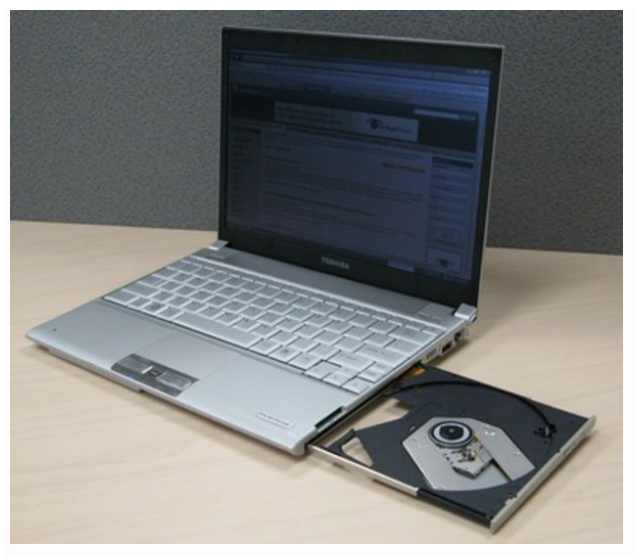

Laptop toshiba yang satu ini adalah laptop pertama dunia tertipis hanya dengan ketebalan $7 \mathrm{~mm}$ dan ukuran 12.1 inch dengan Super-Multi DVD drive.

\section{2. (2008) Toshiba Qosmio G50}

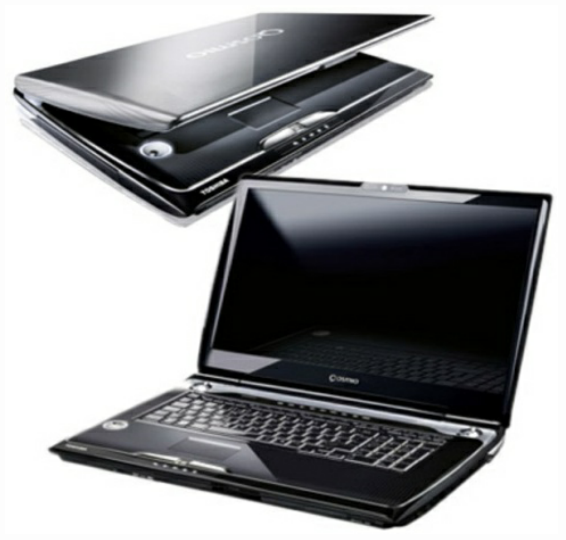

Qosimo G50 dari toshiba ini adalah laptop pertama dengan menggunakan prosesor quad-core di dunia.

13. (2009) SSD 512 GB 


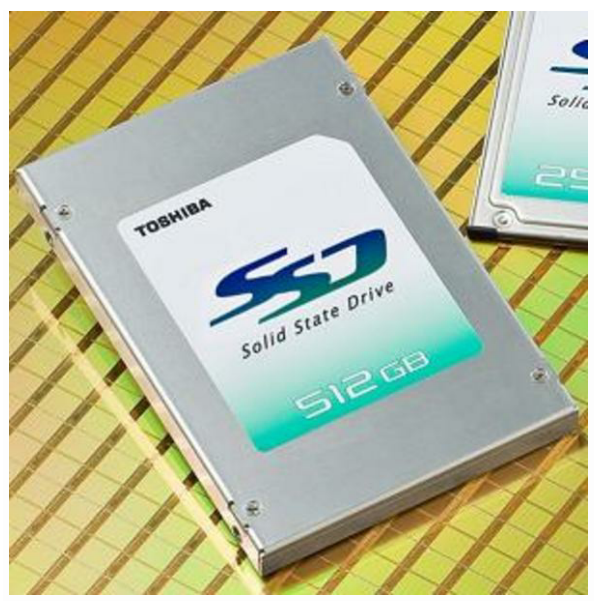

Ini adalah Ultra-portable pertama dengan kapasitas 512GB SSD

14. (2010) Toshiba Libretto W100

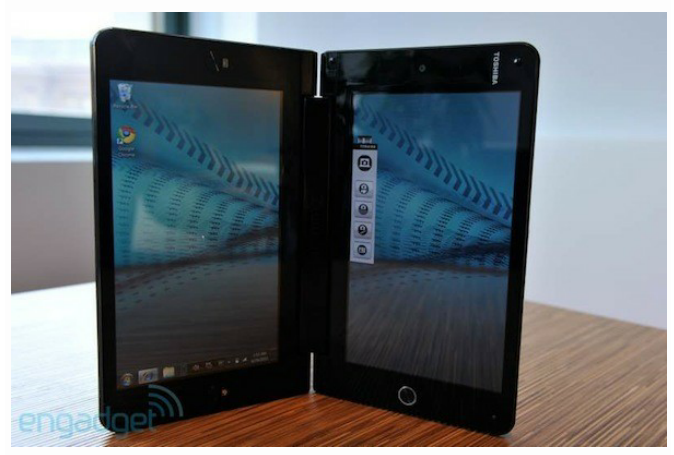

Toshiba Libretto W100, dual touchscreen ukuran 7 inch pertama di dunia. Bentuknya sangat unik.

\section{5. (2011) Toshiba Qosmio F750}

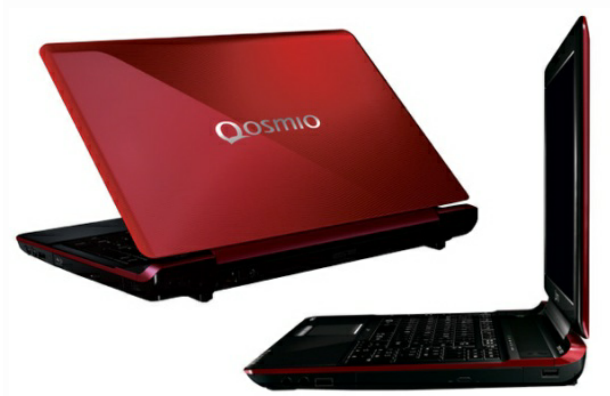

Toshiba Qosmio F750 adalah Laptop pertama di dunia yang berbasis 3D tapi tidak memerlukan kaca.

16. (2012) Toshiba Protege Z830

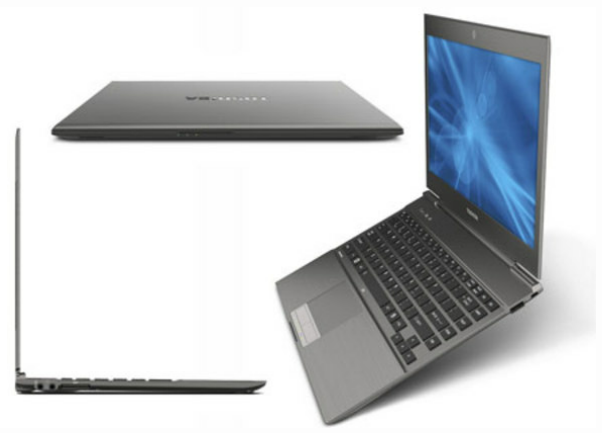

Protege Z830 adalah Ultrabook pertama di dunia yang memiliki konektivitas terlengkap

\#) Selain laptop ada berbagai produk toshiba yaitu

-MOUSE

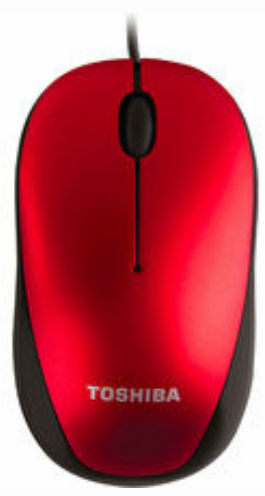

-KAMERA 


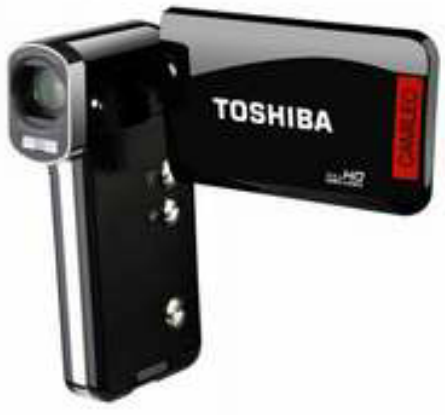

\section{-MEMORY CARD}

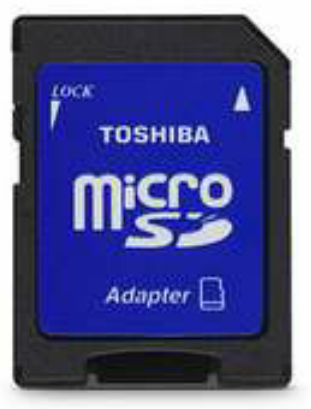

\section{rosyian
Excrion}

-TELEVISI

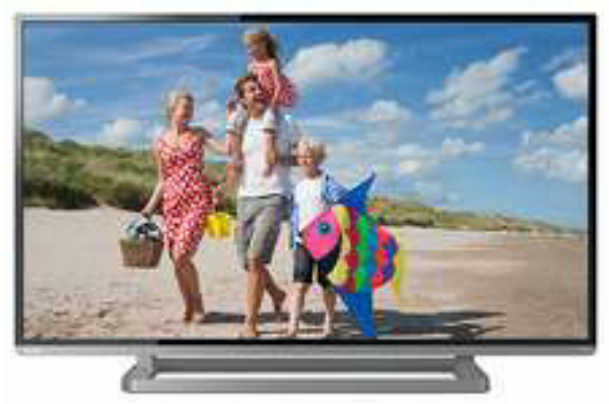

-FLASHDISK

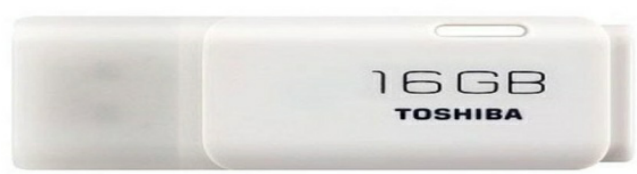

^^) Adapun kekurangan dan kelebihan produk Toshiba :

**) Kelemahan laptop Toshiba:

1. Harga tergolong mahal, namun sesuai dengan dukungan service yang bagus dan spare part yang mudah didapatkan.

2. Desain: bagi sebagian orang desain laptop Toshiba mungkin kurang menarik karena tidak terlalu banyak varian. Namun bagi sebagian lain itu tidak menjadi masalah.

3. Terlalu banyak model dan spek, penamaan model juga tidak jelas jadi banyak yang tertukar, dan salah. Akibatnya pembeli sering salah pilih, contoh Sattelite L745; sebenernya Sattelite L745 ada beberapa spek, yang bisa dibedakan dengan angka dibelakang a8 tersebut, spt Sattelite L745-1204 beda dengan Sattelite L745-1109. Penamaan seperti ini sedikit membingungkan

**)Kelebihan laptop Toshiba:

1. Sudah tidak diragukan lagi, Toshiba adalah salah satu mereka terkemuka di dunia. Hanya saja posisinya tahun ini sedikit tergeser oleh Asus. 
2. Dari segi harga cukup tinggi, namun tentu didukung beberapa kelebihan, yaitu produknya gampang dicari, servis dan spare parts lebih gampang.

3. LCD-nya termasuk yang paling bagus di kelasnya. Tahan lama dan tangguh.

4. Dari segi desain dan konstruksinya lumayan kokoh, dibeberapa seri bahkan ada pelindung HDD, jadi meskipun jatuh bisa tetap terlindungi

\section{ID SECURITY}

QWTD4452377-ASP5244107

\section{KESIMPULAN}

Toshiba adalah perusahaan Jepang yang memproduksi dan memasarkan berbagai peralatan listrik dan produk elektronik yang banyak dimanfaatkan oleh banyak orang untuk membantu kegiatannya ,dan produk yang dihasilkan pun berkualitas tinggi serta telah mempunyai spesifikasi yang maju dan menyamai produk dari merk lain.mulai dari awal semua produknya yang laptop,mouse,flashdisk,telev isi,memory card sungguh menarik minat orang untuk membeli produk toshiba.

\section{E. DISKUSI}

Apakah artikel ini cukup membantu anda?

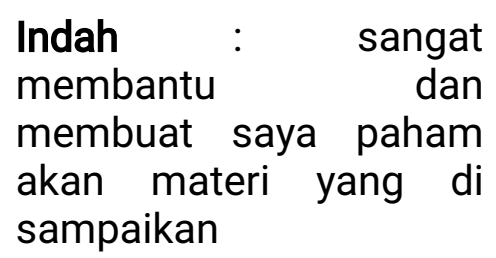

Apakah kekurangan artikel ini?

$\begin{array}{lr}\text { Roni : } & \text { mungkin } \\ \text { penjelasan } & \text { tentang } \\ \text { contoh dari } & \text { setiap poin } \\ \text { artikelnya } & \end{array}$ Apakah kelebihan artikel ini?

Dino : penjelasanya dari setiap poinnya sangat menarik dan cukup membantu

Apakah artikel ini layak di publikasikan?

Tari : layak di publikasikan karna penjelasan tentang bagaimana sebuah produk toshiba layak untuk konsumen

\section{F. REFERENCE}

[1]

O. M. Febriani and A. S. Putra, "Sistem Informasi Monitoring Inventori Barang Pada Balai Riset Standardisasi Industri Bandar Lampung," J. Inform., vol. 13 , no. 1, pp. 90-98, 2014.

[2] A. S. Putra, "Paperplain: Execution Fundamental Create Application With 
Borland Delphi 7.0 University Of Mitra Indonesia," 2018.

[3] A. S. Putra, "2018 Artikel Struktur Data, Audit Dan Jaringan Komputer," 2018.

[4] A. S. Putra, "ALIAS MANAGER USED IN DATABASE DESKTOP STUDI CASE DB DEMOS."

[5] A. S. Putra, "COMPREHENSIVE SET OF PROFESSIONAL FOR DISTRIBUTE COMPUTING."

[6] A. S. Putra, "DATA ORIENTED RECOGNITION IN BORLAND DELPHI 7.0."

[7] A. S. Putra, "EMBARCADERO DELPHI XE 2 IN GPUPOWERED FIREMONKEY APPLICATION."

[8] A. S. Putra, "HAK ATAS KEKAYAAN INTELEKTUAL DALAM DUNIA TEKNOLOGY BERBASIS REVOLUSI INDUSTRI 4.0."

[9] A. S. Putra, "IMPLEMENTASI PERATURAN

PERUNDANGAN UU. NO 31

TAHUN 2000 TENTANG DESAIN INDUSTRI BERBASIS INFORMATION TECHNOLOGY."$$
\text { A. } S \text {. }
$$

"IMPLEMENTATION OF PARADOX DBASE."

[11] A. S. Putra, "IMPLEMENTATION OF TRADE SECRET CASE STUDY SAMSUNG MOBILE PHONE."

[12] A. S. Putra, "IMPLEMENTATION PATENT FOR APPLICATION WEB BASED CASE STUDI WWW. PUBLIKLAMPUNG. COM."

[13] A.

S. Putra,
"IMPLEMENTATION SYSTEM FIRST TO INVENT IN DIGITALLY INDUSTRY."

[14] A. S. Putra, "MANUAL REPORT \& INTEGRATED DEVELOPMENT

ENVIRONMENT BORLAND DELPHI 7.0."

[15] A. S. Putra, "PATENT AS RELEVAN SUPPORT RESEARCH."

[16] A. S. Putra, "PATENT FOR RESEARCH STUDY CASE OF APPLE. Inc."

[17] A. S. Putra, "PATENT PROTECTION FOR APPLICATION INVENT."

[18] A. S. Putra, "QUICK REPORT IN PROPERTY PROGRAMMING."

[19] A. S. Putra, "REVIEW CIRCUIT LAYOUT COMPONENT REQUIREMENT ON ASUS NOTEBOOK."

[20] A. S. Putra, "REVIEW TRADEMARK PATENT FOR INDUSTRIAL TECHNOLOGY BASED 4.0."

[21] A. S. Putra, "TOOLBAR COMPONENT PALLETTE IN OBJECT ORIENTED PROGRAMMING."

[22] A. S. Putra, "WORKING DIRECTORY SET FOR PARADOX 7."

[23] A. S. Putra, "ZQUERY CONNECTION IMPLEMENTED

PROGRAMMING STUDI CASE PT. BANK BCA Tbk."

[24] A. S. Putra, D. R. Aryanti, and I. Hartati, "Metode SAW (Simple Additive Weighting) sebagai Sistem Pendukung Keputusan Guru Berprestasi 
(Studi Kasus: SMK Global Surya)," in Prosiding Seminar Nasional Darmajaya, 2018, vol. 1, no. 1, pp. 85-97.

[25] A. S. Putra and 0. M. Febriani, "Knowledge Management Online Application in PDAM Lampung Province," in Prosiding International conference on Information Technology and Business (ICITB), 2018, pp. 181-187.

[26] A. S. Putra, O. M. Febriani, and B. Bachry, "Implementasi Genetic Fuzzy System Untuk Mengidentifikasi Hasil Curian Kendaraan Bermotor Di Polda Lampung," SIMADA (Jurnal Sist. Inf. dan Manaj. Basis Data), vol. 1, no. 1, pp. 21-30, 2018.

[27] A. S. Putra, H. Sukri, and K. Zuhri, "Sistem Monitoring Realtime Jaringan Irigasi Desa (JIDES) Dengan Konsep Jaringan Sensor Nirkabel," IJEIS (Indonesian J. Electron. Instrum. Syst., vol. 8, no. 2, pp. 221-232.

[28] D. P. Sari, O. M. Febriani, and A. S. Putra, "Perancangan Sistem Informasi SDM Berprestasi pada SD Global Surya," in Prosiding Seminar Nasional Darmajaya, 2018, vol. 1, no. 1, pp. 289-294. 